\title{
ANALISIS PENGARUH PARAMETER PENGELASAN GTAW PADA STAINLESS STEEL AISI 304 TERHADAP SIFAT MEKANIS DAN STRUKTUR MIKRO
}

\author{
Tumpal Ojahan $\mathbf{R}^{1)}$, Yusup Hendronursito ${ }^{2)}$ dan Daniel Anggi S. ${ }^{3)}$ \\ ${ }^{1,3)}$ Program Studi Teknik Mesin, Fakultas Teknik, Universitas Malahayati \\ Jl. Pramuka No 27 Kemiling, Bandar Lampung, Lampung, Telp: 0721271112, Fax: 27119 \\ ${ }^{2)}$ BPTM LIPI, Jl. Ir. Sutami Km.15 Tanjung Bintang, Lampung Selatan, Lampung. \\ e-mail: tumpal_ojahan@yahoo.com
}

\begin{abstract}
Stainless steel common worn in industry because it has the mechanical properties of a strong, the physical properties of a good, can be recycled without reducing the quality of its constituent compound, decorative and easily cleared, resistant to corrosion, capable of preventing contamination so that the use of stainless steel increase significantly. The use of stainless steel can not be separated from the process of welding, hence writer do research by varying discharge a stream of gas $(13,17,21$ liter per minute), current (70,130,180 ampere) And types of electrodes (EWLa-1.5, EWTh-2, EWCe-2) With the design Taguchi L9. The purpose of research to know the influence of parameter against the force pull, violence and structure micro, using of GTAW welding with Taguchi methods. The results of tensile test: yield stress dust the highest to parameter stream of gas 17 liters per minutes, the current 70 ampere, electrodes EWLa-1.5 gold with the $387 \mathrm{MPa}$, maximum stress to the flow of gas 21 liters per minutes, the current 70 ampere, electrodes EWLa-1.5 gold with the $648 \mathrm{MPa}$ and strain to the low of gas 17 liters per minutes, the current 70 ampere, electrodes EWTh-2 red with the 62,2\%. The Rockwell hardness regional of weld to gas flow is 17 liters per minutes, the current 130 ampere, electrodes EWCe-2 grey the hardness poin is 74,2 HRb. Regional HAZ to the gas flow is17 liters per minutes, the current 180 ampere, electrodes EWLa-1.5 gold of 77,3 HRb. Best parameter with the taguchi method to tensile streng of gas flow 21 liter per minutes, the current 70 ampere and types of electrodes EWLa-1.5. Against rockwell hardness test $(\mathrm{HRb})$ found in a stream of gas 17 liter per minutes, the current 130 ampere and types of electrodes EWCe-2.The phase that is formed before welding at micro structure is the phase austenite and the crom, nickel through welding there are adding the phase carbide crom, only the size of the widening weld and haz different.
\end{abstract}

Keywords: GTAW Welding, Taguchi, Stainless Steel 304.

\section{PENDAHULUAN}

Stainless Steel telah banyak digunakan dan diaplikasikan dalam kehidupan sehari-hari karena menawarkan proteksi fisik yang sangat bagus, mudah dibentuk, dekoratif serta dapat didaur ulang tanpa harus mengurangi kualitas senyawa penyusunnya. Campuran Stainless Steel mengandung senyawa kromium dengan presentase sedikitnya $11 \%$ yang cukup untuk dapat membentuk suatu lapisan pasif pada permukaan baja.

Stainless Steel AISI 304 adalah salah satu jenis stainless steel yang umum dipakai pada dunia industri karena memiliki sifat mekanik yang cukup kuat, tahan terhadap korosi, mampu mencegah kontaminasi dan mudah dibersihkan sehingga penggunaannya meningkat secara signifikan seperti alat kesehatan, kaleng pengemas makanan dan minuman, mesin produksi pengolah makanan dan minuman, bidang automotif serta peralatan rumah tangga bahkan fasilitasfasilitas umum maupun bidang konstruksi. Setiap penggunaan Stainless Steel tidak lepas dari proses penyambungan dengan pengelasan, oleh karena itu penulis melakukan penyambungan las pada material Stainless Steel AISI 304 dengan memvariasikan debit aliran gas, arus dan jenis elektrodanya. Proses pengelasan las yang digunakan Gas Tungsten Arc Welding (GTAW) dimana masing-masing parameter las akan mempengaruhi sifat fisis maupun sifat mekanik dari baja tersebut.

Menurut DIN (Deutsche Industrie Normen) las adalah ikatan metalurgi pada sambungan logam paduan yang dilakukan dalam keadaan lumer atau cair/dapat juga diartikan sebagai satu cara untuk menyambung dua atau lebih bagian logam secara permanen dengan menggunakan tenaga panas. Las GTAW (Gas Tungsten Arc Welding) adalah pengelasan dengan menggunakan busur 
nyala yang dihasilkan oleh elektroda tetap terbuat dari tungsten. Sebagai bahan penambah (filler) terbuat dari bahan yang sama atau sejenis dengan bahan yang dilas dan terpisah dari stang las (Welding Torch) [1].

Metode Taguchi adalah metode eksperimen yang bertujuan untuk memperbaiki kualitas suatu produk dan proses dalam waktu bersamaan untuk menekan biaya seminimal mungkin sehingga dicapai kondisi yang optimal dan efisien [2]. Metode Taguchi menggunakan seperangkat matriks khusus yang disebut Orthogonal Array, Bagian penting terletak pada pemilihan kombinasi level variabel-variabel input untuk masing-masing percobaan. Matriks ini merupakan langkah untuk menentukan jumlah percobaan minimal yang dapat memberikan informasi sebanyak mungkin semua faktor yang mempengaruhi parameter [3]. Taguchi memperkenalkan pendekatan S/N Ratio untuk meneliti pengaruh faktor noise terhadap variasi yang timbul. Jenis $\mathrm{S} / \mathrm{N}$ ratio tergantung pada karakteristik yang dinginkan, yaitu:

\section{Smaller The Better (STB)}

Karakteristik kualitas, semakin rendah nilainya maka kualitas semakin baik dalam mencari nilai kekasaran permukaan optimum proses permesinan, semakin kecil nilai kekasaran permukaan maka semakin baik. Adapun rumus untuk mencari nilai Smaller The Better (STB) adalah sebagai berikut:

$\frac{\mathrm{s}}{\mathrm{N}}=-10 \log \left[\frac{1}{\mathrm{n}} \sum_{\mathrm{i}=1}^{\mathrm{n}} \mathrm{yi}^{2}\right]$

dengan $\mathrm{n}=$ jumlah tes didalam percobaan

\section{Larger The Better (LTB)}

Karakteristik kualitas, semakin besar nilainya maka kualitas semakin baik dalam semakin besar nilai kekerasan suatu material Contohnya adalah umur pahat, semakin lama waktu yang digunakan maka sebaik. Adapun rumus untuk mencari nilai Larger The Better (LTB) adalah sebagai berikut:

$\frac{\mathrm{s}}{\mathrm{N}}=-10 \log \left[\frac{1}{\mathrm{n}} \sum_{\mathrm{i}=1}^{\mathrm{n}} \frac{1}{\mathrm{yi}^{2}}\right]$

\section{Nominal The Better (NTB)}

Karakteristik kualitas ditetapkan suatu nilai nominal tertentu, jika nilainya semakin mendekati nilai nominal tertentu maka kualitasnya semakin baik. Adapun rumus untuk mencari nilai Nominal The Better (NTB) adalah sebagai berikut:

$\frac{\mathrm{S}}{\mathrm{N}}=-10 \mathrm{Log} \cdot$ Ve (untuk variansi saja)

$\frac{\mathrm{S}}{\mathrm{N}}=-10 \mathrm{Log} \cdot\left[\frac{\mathrm{Vm}-\mathrm{Ve}}{\mathrm{Ve}}\right]($ rata - rata dan variansi $)$

Menurut Yudhistira N. [4] pengaruh variasi kuat arus dan gas lindung terhadap kekuatan tarik hasil las TIG pada bahan stainless steel AISI 304 dapat disimpulkan bahwa tidak ada pengaruh yang signifikan dari variabel kuat arus, gas lindung, maupun interaksi keduanya terhadap kekuatan tarik hasil las GTAW. Parameter argon UHP, arus 160 A memiliki kekuatan tarik daerah lasan mendekati kekuatan tarik ideal stainless steel AISI 304. Sedangkan kekuatan tarik daerah lasan terendah adalah pengelasan menggunakan argon UHP, arus 120 A. Terjadi peningkatan kekuatan tarik pada variasi gas argon UHP setiap peningkatan arusnya, berbeda dengan variasi gas helium UHP terjadi penurunan kekuatan tarik pada setiap peningkatan arusnya. 
Menurut Kuncoro W.U. [5] Analisa Pengaruh Besar Arus pada Pengelasan TIG Metode Striking dan Weaving Terhadap Kekerasan dan Struktur Mikro Stainless Steel 304 dapat disimpulkan bahwa semakin besar arus yang digunakan semakin kecil butiran atom pada struktur mikronya, sedangkan pada proses pengelasan metode striking dan weaving pada jarak $2 \mathrm{~mm}$ dari pusat pengelasan memiliki nilai kekerasan lebih kecil dibandingkan dengan jarak uji $10 \mathrm{~mm}$, karena jarak $2 \mathrm{~mm}$ tersebut termasuk daerah logam las. Daerah HAZ metode weaving lebih luas dibanding metode striking, serta semakin besar arus mempengaruhi luas daerah HAZ. Pada dasarnya metode weaving mempengaruhi luas daerah HAZ dibanding metode striking dengan variasi arus 80A, $120 \mathrm{~A}$ dan 160A tetapi tidak ada perbedaan nilai kekerasan.

Menurut Yunus Y. [6] Variasi Arus Listrik Terhadap Sifat Mekanik Mikro Sambungan Las Baja Tahan Karat AISI 304 dapat disimpulkan bahwa nilai kekerasan Vickers tertinggi terdapat pada penggunaan kuat arus 40 A (benda uji II) yaitu sebesar $226 \mathrm{~kg} / \mathrm{mm}^{2}$, kekuatan tarik maksimum terjadi pada benda uji II (40 A) sebesar $698 \mathrm{~N} / \mathrm{mm}^{2}$. Hal ini disebabkan karena struktur mikro daerah HAZ pada benda uji II (40 A) berupa austenit yang paling sedikit ditemukannya endapan karbid chrome dibandingkan dengan struktur mikro dari daerah HAZ benda uji I (30A) dan benda uji III (50A).

\section{METODE PENELITIAN \\ Persiapan Bahan}

Bahan yang diperlukan dalam penelitian ini adalah stainless steel AISI 304 dengan ukuran panjang $1000 \mathrm{~mm}$, lebar $200 \mathrm{~mm}$, tebal $3 \mathrm{~mm}$. Dipotong menggunakan mesin potong sesuai ukuran sampel yang telah ditentukan. Sampel dilas menggunakan las GTAW dengan gas argon. Variasi elektroda yang digunakan antara lain elektroda EWTh-2, EWLa-1.5 dan EWCe-2. dengan standar AWS A5. 12M [7]. Masing-masing elektroda berdiameter 3,2 mm.

\section{Proses Pengelasan}

Untuk keselamatan dan keamanan mesin las GTAW harus memiliki SOP atau prosedur penggunaan alat. Sebelum proses pengelasan dilakukan, permukaan benda kerja harus dibersihkan dari oli, kerak, cat atau debu. Langkah-langkah yang dilakukan dalam proses las GTAW dalam memastikan kabel utama pesawat las sudah dipasang dengan benar pada sumber listrik. Pada saat pemasangan kabel utama pada sumber arus kondisi pesawat las harus dalam kondisi OFF. Mulai pengecekan pada regulator, tekanan gas dan volume gas serta saluran pendingin kemudian setel besar arus 70A, 130A, 180A, setel aliran gas pelindung dimulai dari 13, 17, 21 liter/menit. Dalam keselamatan kerja perlu menggunakan helm las, kaca mata, sarung tangan dan baju las. Langkah selanjutnya menyiapkan benda kerja pada meja kerja dengan menjepit tang massa pada benda kerja atau meja kerja dengan kencang. Tahap pengelasan menyalakan pembangkitan busur awal dengan menggoreskan ujung elektroda tungsten pada benda kerja (Striking of Arc), hingga mendapatkan busur yang stabil dengan menjaga jarak ujung elektroda dan permukaan benda kerja ditahan pada $1,5 \mathrm{~mm}$ hingga $3 \mathrm{~mm}$. Pegaturan jarak ini juga berlaku untuk semi otomatis atau otomatis penuh. Posisi stang las ditahan pada sudut $60^{\circ}-85^{\circ}$ lalu jalankan stang las pada daerah yang akan dilas dan atur kecepatan pengelasan serta ayunan tangan agar hasil lasan tidak melebar. Ulangi langkah diatas sesuai parameter yang digunakan.

\section{Pengujian Komposisi Kimia}

Pengujian ini bertujuan untuk mengetahui prosentase unsur-unsur penyusun sampel benda uji, peralatan yang digunakan adalah spektrum komposisi kimia (Optical Emission Spectrometer) yang dilakukan di Laboraturium Balai Penelitian Teknologi Mineral LIPI Tanjung Bintang. Pada pengujian ini memerlukan material dengan ukuran 50 mm X 50 mm dengan tebal 3 mm. 


\section{Pengujian Tarik}

Pengujian tarik adalah untuk memperoleh sifat-sifat mekanis material, yaitu mengenai tegangan maksimum, tegangan luluh dan regangan. Mesin uji yang digunakan adalah mesin uji tarik universal AMSLER 20 Ton yang dihubungkan dengan plotter yang menghasilkan grafik pembebanan $(\mathrm{kg})$ dan pertambahan panjang. Adapun tahapan-tahapan yang akan dilakukan pada proses pengujian tarik adalah menyiapkan sampel uji tarik sesuai standar (ASTM/E8/E8M) [8], ukur parameter awal yang diperlukan seperti panjang mula-mula (Lo), tebal (t) dan lebar (w). Selanjutnya pompakan oli atau fluida untuk penggerak hidrolik sebelum mesin dihidupkan dan siapkan pencekam sesuai bentuk dan ujuran sampel uji kemudian memasang kertas milimeter block untuk memperoleh hasil pencatatan data berupa grafik hasil pengujian dari mesin. Menghidupkan mesin uji tarik dan menunggu \pm 10 menit agar hidrolik siap dioperasikan. Langkah selanjutnya memasang sampel pada pencekam dengan benar dan kuat agar tidak terjadi slip, untuk mengatur kedudukan sampel gunakan tombol cross head up dan down. Tempatkan pena pada kertas grafik untuk memperoleh kurva hasil penarikan sampel tersebut. Mengatur jarum indikator jarum hitam dan jarum merah pada posisi nol start (0). Mulai penarikan dengan membuka katup hidrolik kanan secara perlahan dan konstan sampai sampel putus, lalu tutup kembali katup hidrolik tersebut. Selanjutnya mengambil kertas milimeter untuk dianalisa, lepaskan sampel dari pencekamnya dan lakukan pengukuran pada sampel yang telah putus untuk memperoleh hasil yang diperlukan yaitu panjang sampel yang telah putus $(\mathrm{Li})$.

\section{Pengujian Kekerasan}

Pengujian kekerasan dilakukan untuk mengetahui distribusi kekerasan antara logam induk (Base Metal), daerah sekitar lasan HAZ (Heat Affected Zone) dan daerah logam lasan (Weld Metal) dari benda uji sehingga dapat diketahui harga kekerasan serta kekerasan rata-rata dari benda uji. Alat uji kekerasan menggunakan Macro Rockwell Hardness Tester. Langkah-langkah yang yang dilakukan dalam pengujian kekerasan adalah memasang indentor bola baja HRB. Penekanan bola baja Ø 1/16" dipasang pada tempat indentor mesin uji, kencangkan secukupnya agar penekan intan tidak jatuh dan lakukan kalibrasi pada indikator nilai kekerasan Rocwell B. Untuk memudahkan dalam pengujian perlu garis warna dan menentukan titik yang akan diuji pada daerah logam las, HAZ, dan logam induk yang akan diuji. Selanjutnya menentukan beban sebesar $100 \mathrm{kgf}$ dan pasangkan sampel uji diatas landasan, putar landasan sampai indentor menekan titik yang diinginkan pada sampel dan dorong tuas loading pembebanan, tunggu sampai jarum indikator berhenti kemudian menariknya kembali dan catat nilai kekerasan.

\section{Foto Struktur Mikro}

Pengujian struktur mikro bertujuan untuk mengetahui struktur logam yang berukuran mikroskopis dan membandingkan sifat-sifat yang dimilikinya. Daerah yang di foto struktur mikronya adalah daerah lasan, daerah HAZ dan daerah logam induk. Adapun prosedur yang dilakukan pada pemeriksaan struktur mikro adalah memotong sampel dan melakukan proses pembingkaian sampel agar mudah untuk memegang sampel selain itu untuk melindungi dari kerusakan sampel selama proses penggosokan. Selanjutnya sampel yang akan digunakan dalam pengujian struktur mikro diamplas dan dipoles terlebih dahulu agar permukaannya bersih dari partikel-partikel asing serta memperoleh permukaan yang rata. Proses pengamplasan dilakukan dari amplas yang ukurannya kasar sampai yang ukurannya paling halus selanjutnya sampel dipoles menggunakan kain beludru. Sampel harus dibersihkan terlebih dahulu, setelah dibersihan kemudian dimasukan dalam cairan etsa dengan menggunakan larutan $\mathrm{FeCl}_{3}$ dengan cara dicelupkan kedalam larutan $\mathrm{FeCl}_{3}$ dalam waktu 1 - 2 menit. Setelah proses etsa selesai sampel dibilas dengan alkohol dan air biasa, setelah kering sampel siap difoto stuktur mikro. Larutan $\mathrm{FeCl}_{3}$ dibuat dengan $5 \mathrm{gr}$ $\mathrm{FeCl}_{3}$ dicampur dengan $50 \mathrm{ml} \mathrm{HCl}$ dan $100 \mathrm{ml} \mathrm{H}_{2} \mathrm{O}$ [9]. Tujuan dari proses ini yaitu untuk memperjelas batas butir dan struktur mikronya. Setelah sampel di etsa, proses dilanjutkan dengan 
pengamatan dibawah mikroskop. Hal ini bertujuan untuk mengamati struktur mikro dari tiap-tiap sampel. Pengamatan dibawah mikroskop ini menggunakan pembesaran $100 \mu \mathrm{m}, 50 \mu \mathrm{m}$ dan $10 \mu \mathrm{m}$. Apabila struktur mikro yang diinginkan telah didapat, langkah selanjutnya adalah pemotretan menggunakan kamera yang menyatu dengan mikroskop. Mikroskop yang digunakan adalah model Nikon Eclipse MA 100.

\section{Foto Mesin Uji}

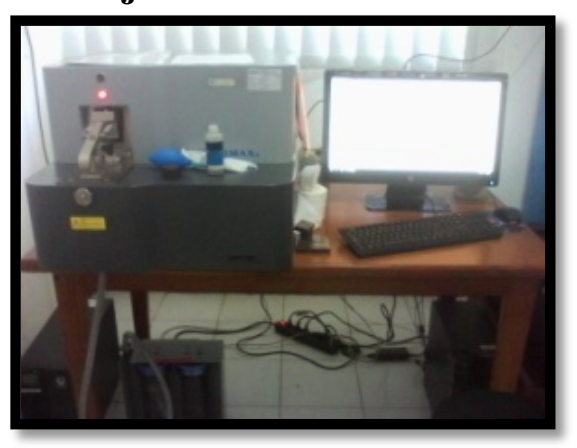

Gambar 1. Mesin uji komposisi kimia

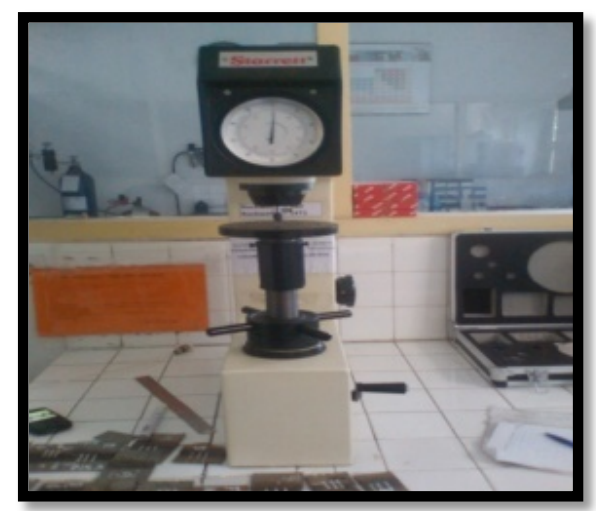

Gambar 3. Mesin uji kekerasan Rockwell

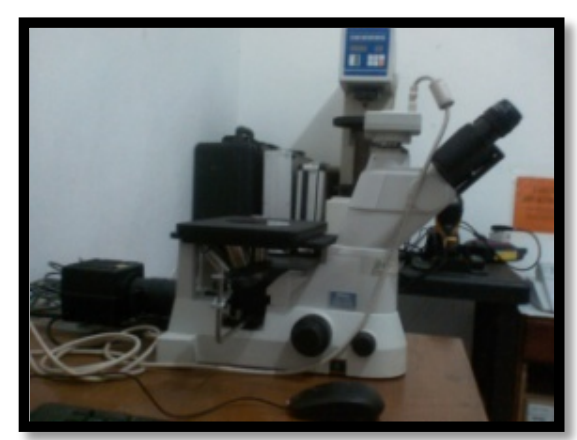

Gambar 2. Mesin foto struktur mikro

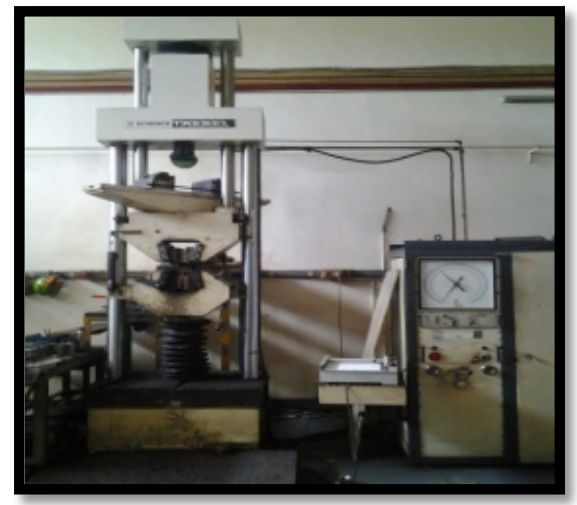

Gambar 4. Mesin uji tarik AMSLER 20 Ton

\section{HASIL DAN PEMBAHASAN \\ Hasil Uji Komposisi Kimia}

Pengujian komposisi kimia dilakukan pada bahan penelitian untuk mengetahui kandungan dan persentase unsur kimia yang ada didalam material stainless steel dengan hasil pengujian sebagai berikut:

Tabel 1. Komposisi kimia

\begin{tabular}{llc}
\hline Unsur & Lambang & Kadar $\%$ \\
\hline Besi & $\mathrm{Fe}$ & 71,3 \\
Crom & $\mathrm{Cr}$ & 17,42 \\
Nikel & $\mathrm{Ni}$ & 8,37 \\
Mangan & $\mathrm{Mn}$ & 1,61 \\
Silikon & $\mathrm{Si}$ & 0,447 \\
Kobalt & $\mathrm{Co}$ & 0,313 \\
Vanadium & $\mathrm{V}$ & 0,278 \\
Karbon & $\mathrm{C}$ & 0,0637 \\
Tembaga & $\mathrm{Cu}$ & 0,0277 \\
Fospor & $\mathrm{P}$ & 0,0225 \\
Molibden & $\mathrm{Mo}$ & 0,0141 \\
\hline
\end{tabular}




\section{Hasil Uji Tarik}

Berdasarkan pengujian uji tarik yang dilakukan, diperoleh hasil sebagai berikut:

Tabel 2. Hasil pengujian tarik

\begin{tabular}{|c|c|c|c|c|c|c|c|c|}
\hline \multirow{3}{*}{ Sampel } & \multicolumn{8}{|c|}{ Hasil Uji Tarik } \\
\hline & \multirow{2}{*}{$\begin{array}{c}\text { Beban } \\
\text { Mulur } \\
\text { Kgf }\end{array}$} & \multirow{2}{*}{$\begin{array}{c}\text { Beban } \\
\text { Maks } \\
\text { Kgf }\end{array}$} & \multicolumn{2}{|c|}{$\sigma_{\text {Luluh }}$} & \multicolumn{2}{|c|}{$\sigma_{\text {Maksimal }}$} & \multirow{2}{*}{$\begin{array}{l}\Delta \mathrm{L} \\
\mathrm{mm}\end{array}$} & \multirow{2}{*}{$\begin{array}{c}\varepsilon \\
\%\end{array}$} \\
\hline & & & $\mathrm{Kgf} / \mathrm{mm}^{2}$ & Мpa & $\mathrm{Kgf} / \mathrm{mm}^{2}$ & $\mathrm{MPa}$ & & \\
\hline Base & 1300 & 2200 & 39,0 & 382 & 66,0 & 647 & 23,6 & 47,20 \\
\hline 1 & 1535 & 2530 & 39,0 & 382 & 64,3 & 630 & 24,5 & 49,0 \\
\hline 2 & 1088 & 2180 & 32,1 & 314 & 64,2 & 630 & 27,6 & 55,2 \\
\hline 3 & 1038 & 2100 & 28,2 & 276 & 57,0 & 559 & 18,4 & 36,8 \\
\hline 4 & 1365 & 2400 & 35,0 & 343 & 61,6 & 603 & 31,1 & 62,2 \\
\hline 5 & 1383 & 2100 & 39,5 & 388 & 60,0 & 588 & 25,3 & 50,5 \\
\hline 6 & 1220 & 2300 & 34,5 & 338 & 65,0 & 638 & 25,0 & 50,0 \\
\hline 7 & 1140 & 1920 & 38,8 & 380 & 65,3 & 641 & 26,5 & 52,9 \\
\hline 8 & 1403 & 2300 & 39,1 & 384 & 64,2 & 629 & 28,2 & 56,3 \\
\hline 9 & 740 & 2220 & 22,0 & 216 & 66,1 & 648 & 26,3 & 52,6 \\
\hline
\end{tabular}

Analisis metode Taguchi menggunakan pendekatan S/N Ratio dilakukan untuk mencari parameter yang terbaik pada pengelasan GTAW terhadap sifat mekanik Stainless Steel AISI 304.

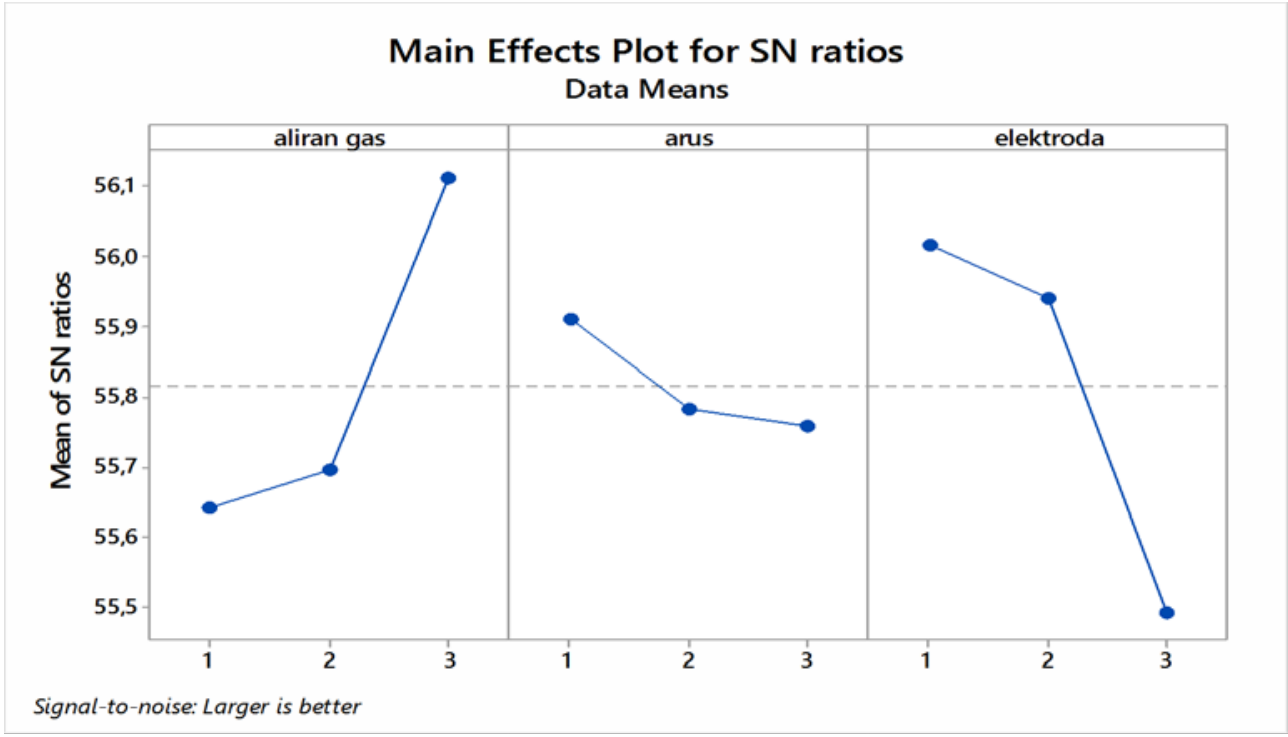

Gambar 5. Grafik uji tarik terhadap parameter terbaik

Berdasarkan analisa metode Taguchi dengan pendekatan SN Ratio menggunakan penilaian Large Is Beter diperoleh parameter yang terbaik terhadap kuat tarik adalah aliran gas 21 liter/menit, arus 70 amper dan jenis elektroda EWLa-1.5.

\section{Uji Kekerasan Rockwell}

Pengujian kekerasan Rockwell merupakan pengujian untuk menentukan kekerasan bahan menggunakan indentor intan (HRB) dengan beban minor $10 \mathrm{kgf}$ dan beban mayor 90 kgf. Pengujian kekerasan dilakukan pada daerah las, HAZ dan logam induk dengan jumlah 5 titik dan 3 kali pengulangan. 
Tabel 3. Hasil rata-rata pengujian kekerasan Rockwell

\begin{tabular}{cccc} 
Sampel & Base & WM & HAZ \\
\hline 1 & 81,0 & 70,5 & 74,7 \\
2 & 81,0 & 73,2 & 74,3 \\
3 & 81,0 & 71,8 & 74,5 \\
4 & 81,0 & 72,3 & 75,0 \\
5 & 81,0 & 74,0 & 71,8 \\
6 & 81,0 & 74,3 & 77,3 \\
7 & 81,0 & 73,0 & 74,3 \\
8 & 81,0 & 69,0 & 75,7 \\
9 & 81,0 & 66,0 & 73,5 \\
\hline
\end{tabular}

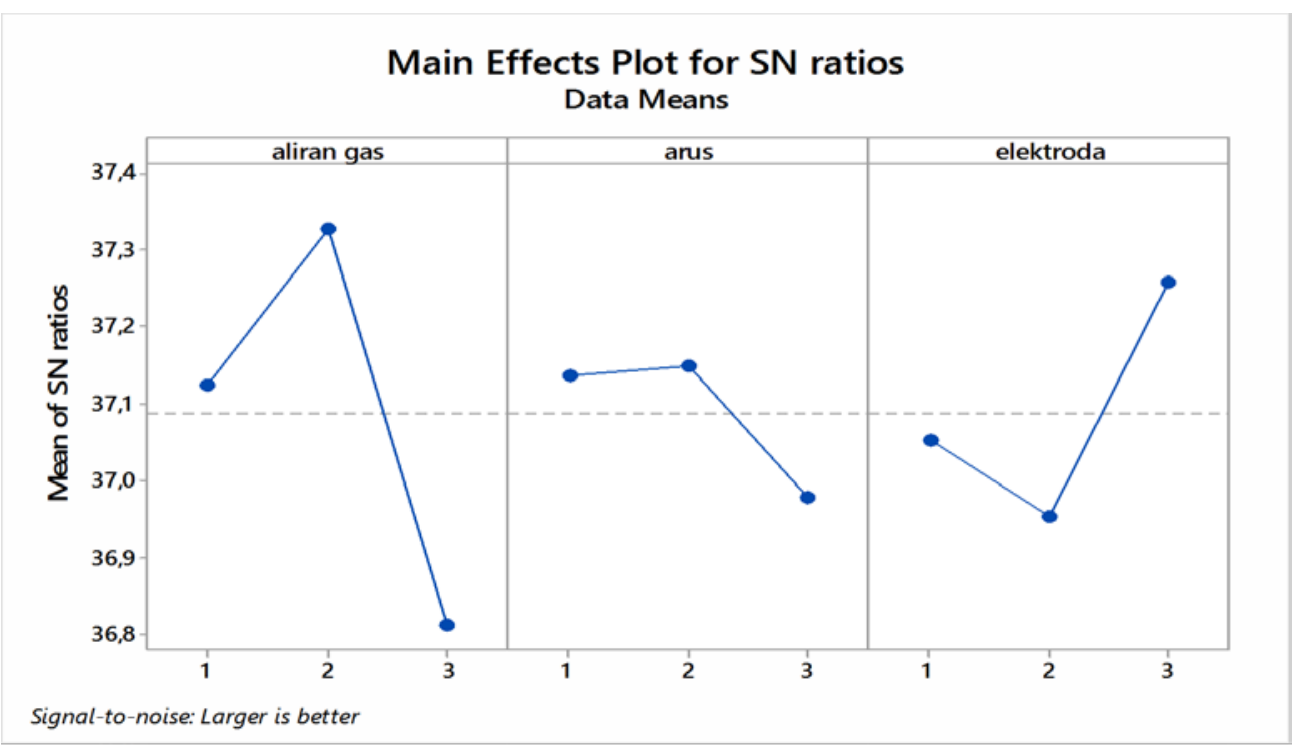

Gambar 6. Grafik kekerasan Rockwell (HRB) terhadap parameter terbaik

Berdasarkan analisa metode Taguchi dengan pendekatan SN Ratio menggunakan penilaian Large Is Beter diperoleh parameter yang terbaik terhadap kekerasan Rockwell (HRB) adalah aliran gas 17 liter/menit, arus 130 Amper dan jenis elektroda EWCe-2.

\section{Hasil Uji Struktur Mikro}

Hasil Pengamatan struktur mikro dapat dilihat pada gambar struktur mikro daerah Weld Metal, HAZ dan Base Metal.

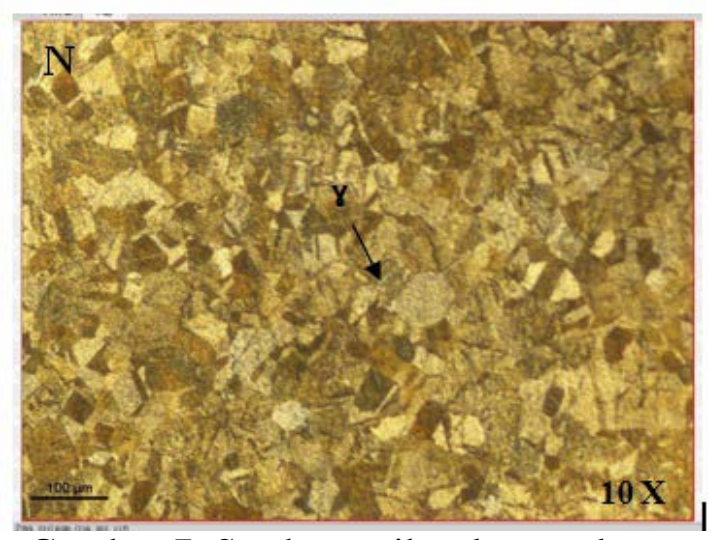

Gambar 7. Struktur mikro logam dasar

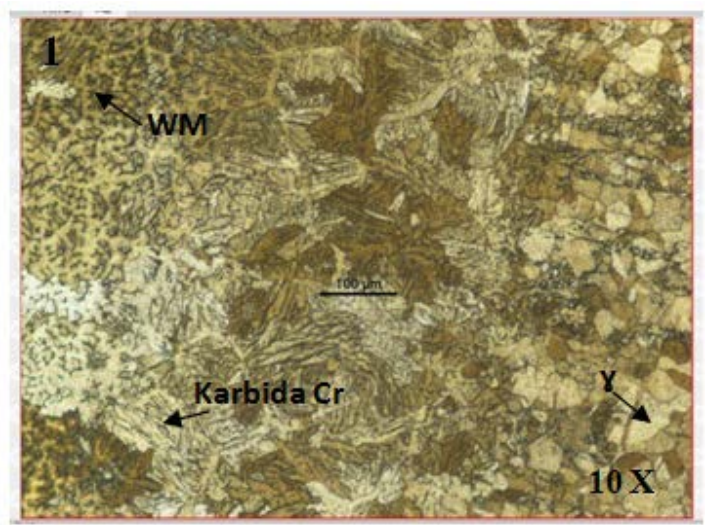

Gambar 8. Struktur mikro pengelasan parameter $13 \mathrm{~L} / \mathrm{M}, 70 \mathrm{~A}$, EWTh-2 


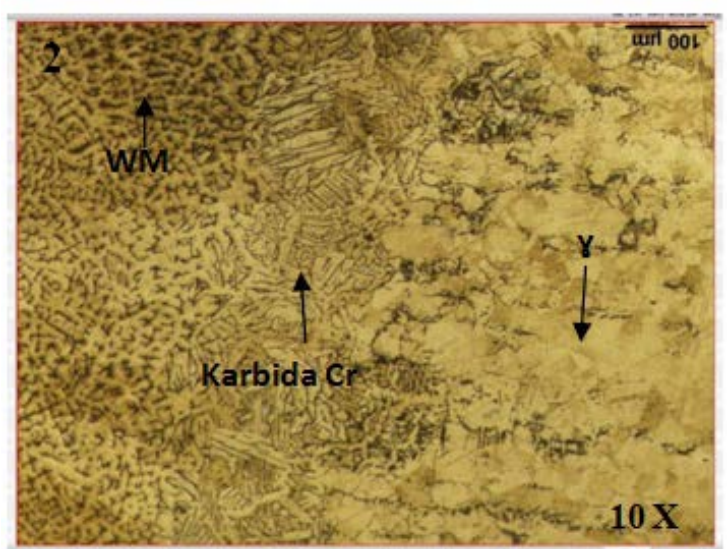

Gambar 9. Struktur mikro pengelasan parameter $13 \mathrm{~L} / \mathrm{M}, 130 \mathrm{~A}$, EWLa - 1.5

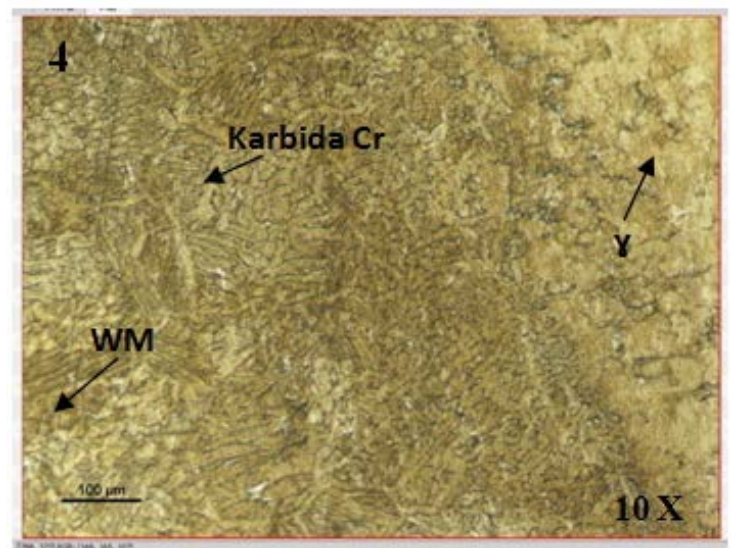

Gambar 11. Struktur mikro pengelasan parameter 17 L/M, 70 A, EWLa - 1.5

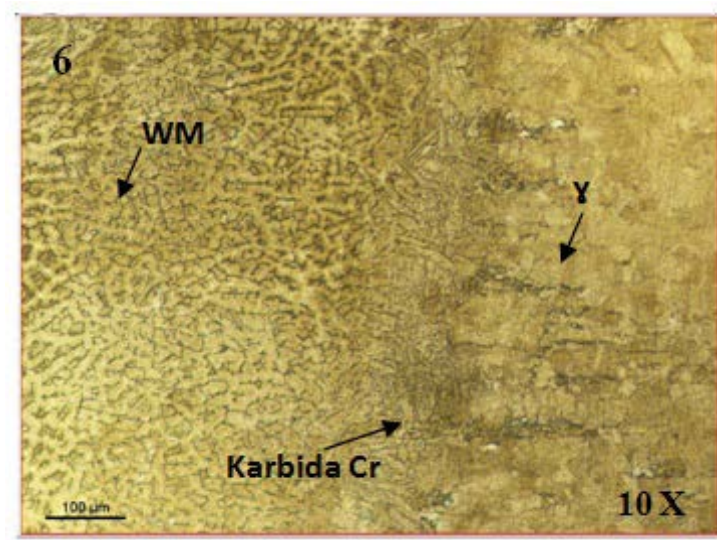

Gambar 13. Struktur mikro pengelasan parameter 17 L/M, 180 A, EWTh - 2

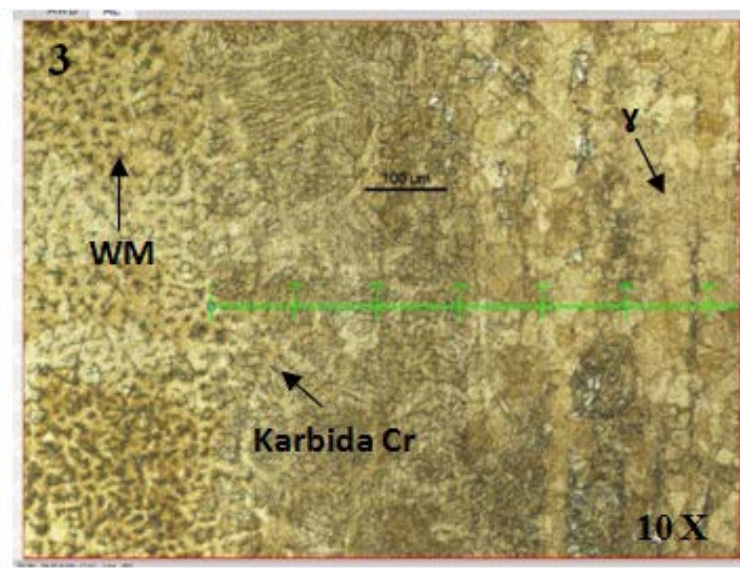

Gambar 10. Struktur mikro pengelasan parameter 13 L/M, 180 A, EWCe - 2

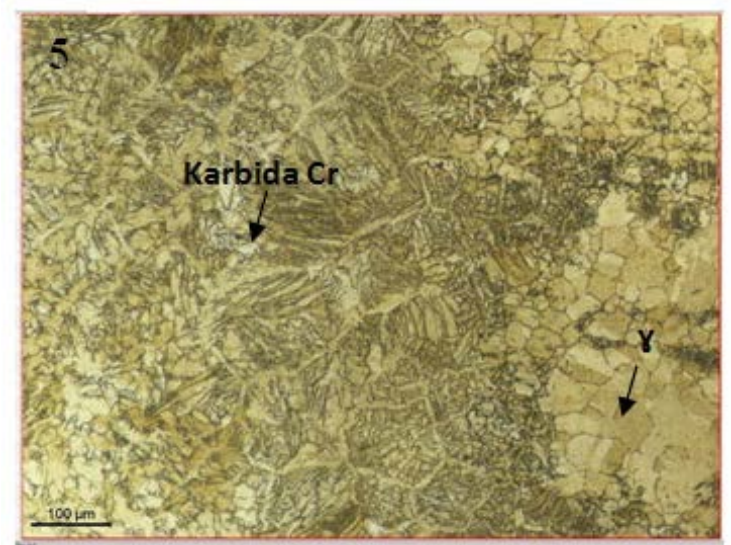

Gambar 12. Struktur mikro pengelasan parameter 17 L/M, 130 A, EWCe - 2

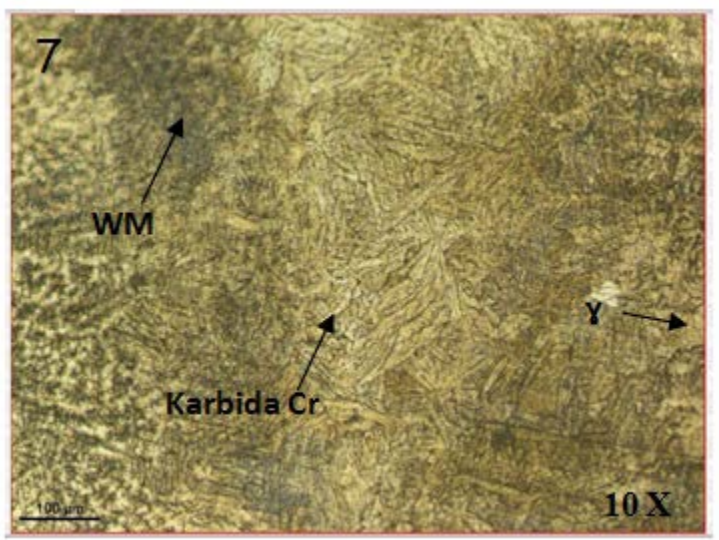

Gambar 14. Struktur mikro pengelasan parameter 21 L/M, 70 A, EWCe - 2

\section{Pembahasan Struktur Mikro}

Hasil pengujian foto struktur mikro menunjukan bahwa baik pada bagian logam induk, daerah HAZ, maupun weld metal semuanya memiliki fasa austenitic $(\gamma)$. Hal ini karena sifat dasar logam induk adalah fasa austenitic yang tidak mengandung magnet. Pada stainless steel AISI 304 ini juga sudah jelas menunjukan bahwa fasa yang dimiliki adalah austenitic. Daerah las pada daerah las karena panas yang terserap lebih banyak, maka struktur austenite dan nikel tampak lebih 
dominan dan struktur yang terlihat pada dengan batas butir yang kecil. Hal ini disebabkan struktur karbida chrome yang terlarut lebih banyak. Daerah HAZ pada daerah ini chrome dan karbida chrome mulai tampak dengan struktur butiran yang besar dan tidak merata di semua bagian sehingga menjadikan pada daerah ini lebih getas dibanding daerah base metal. Daerah logam induk, pada daerah logam induk struktur chrome terlihat merata disemua daerah asutenit serta nikel juga tampak lebih merata. Besar struktur butiran relatif lebih besar dan jika dikaitkan dengan nilai kekerasan daerah base ini harga kekerasan lebih tinggi dari daerah HAZ dan las.

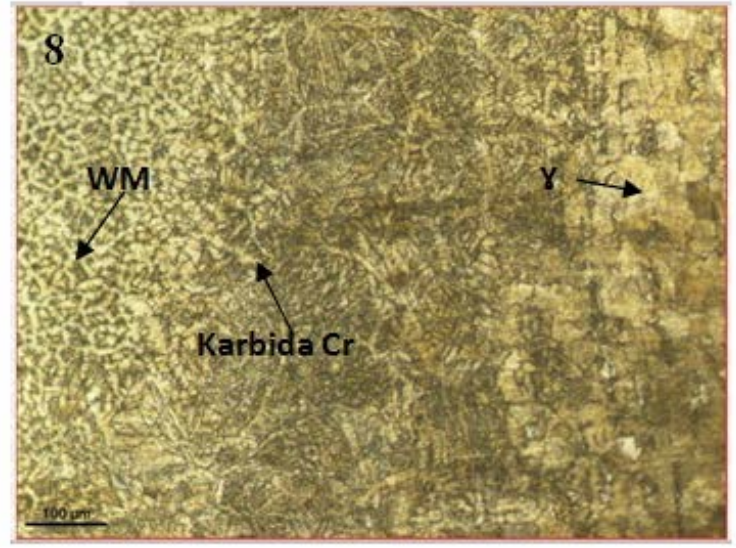

Gambar 15. Struktur mikro pengelasan parameter $21 \mathrm{~L} / \mathrm{M}, 130 \mathrm{~A}$, EWTh - 2

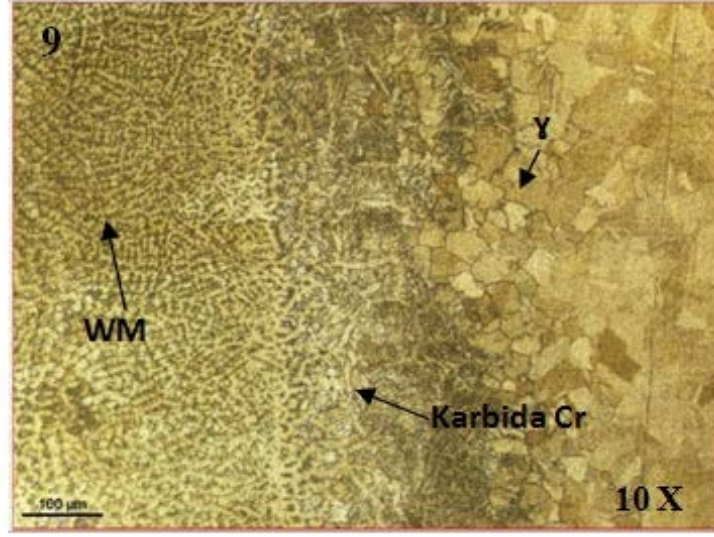

Gambar 16. Struktur mikro pengelasan parameter $21 \mathrm{~L} / \mathrm{M}, 180 \mathrm{~A}, \mathrm{EWLa}-2$

\section{SIMPULAN}

Dari hasil analisa data yang dilakukan dapat disimpulkan beberapa hal sebagai berikut: 1) Parameter yang terbaik terhadap pengujian tarik sambungan lasan terdapat pada aliran gas 17 liter/menit, arus 70 A dan jenis elektroda EWTh-2. 2) Parameter yang terbaik terhadap kekerasan Rockwell daerah weld metal dan daerah HAZ terdapat pada dengan aliran gas 17 liter/menit dan arus 180 A serta jenis elektroda EWLa-1.5. 3) Struktur mikro pada pengelasan dengan parameter aliran gas, arus dan jenis elektroda menghasilkan struktur yang sama, yaitu terdapatnya fasa austenite dan unsur chrome, nikel dan karbida chrome.

\section{DAFTAR PUSTAKA}

[1]. Sri Widharto, 2013, Welding Inspection, Edisi Asli-Mitra Wacana Media, Jakarta.

[2]. Irwan Soejanto, 2009, Desain Eksperimen Dengan Metode Taguchi, Edisi Pertama-Graha Ilmu, Yogyakarta.

[3]. Zulhendri dan Yusri, 2008, Penggunaan Metode Parameter Taguchi Dalam Mengidentifikasi Kekesaran Permukaan Optimum Proses Bubut, Jurnal Teknik Mesin, Vol 5 No. 2, Politeknik Negri Padang.

[4]. Yudhistira Nizar, 2008, Pengaruh Variasi Kuat Arus Dan Gas Lindung Terhadap Kekuatan Tarik Hasil Las Tig Pada Bahan Stainless Steel AISI 304, Skripsi-Universitas Negeri Malang, Malang.

[5]. Kuncoro Wahyu Utomo, 2009, Analisa Pengaruh Besar Arus Pada Pengelasann GTAW Metode Striking Dan Weaving Terhadap Kekerasan Dan Struktur Mikro Stainless Steel 304, Skripsi-Universitas Negeri Malang, Malang.

[6]. Yunus Yakub, 2013, Variasi Arus Listrik Terhadap Sifat Mekanik Mikro Sambungan Las Baja Tahan Karat AISI 304, E-Journal WIDYA Eksakta, Vol 01, No. 01 PP. 7-11.

[7]. AWS, 2009, Specification for Tungsten and Oxide Dispersed Tungsten Electrodes for Arc Welding and Cutting, 7th Edition, American National Standards Institute, USA. 
[8]. Mannual Book of ASTM Standards, 2010, ASTM E8/E8M-9 Standard Test Methods For Tension Testing of Metallic Materials, Copy Right 2010.

[9]. Yuda Prasetya, 2015, Modul Training Teknik Analisa Struktur Mikro Material, LIPI, CMPFA, Fakultas Teknik Universitas Indonesia. 